Received: 09/07/2018

Revision: 18/11/2018

Accepted: 23/11/2018

OnlineFirst: $16 / 12 / 2018$

\title{
The Misconception Diagnosis on Ionic and Covalent Bonds Concepts with Three Tier Diagnostic Test
}

\section{Anti Kolonial Prodjosantoso}

Prof., Department of Chemistry Education, Yogyakarta State University, Yogyakarta, Indonesia, prodjosantoso@uny.ac.id

\section{Artanti Mulia Hertina}

Department of Chemistry Education, Yogyakarta State University, Yogyakarta, Indonesia

\section{Irwanto}

M.Pd., Department of Chemistry Education, Yogyakarta State University, Yogyakarta, Indonesia

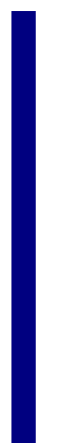

The purpose of this research was to understand the misconception level of 10th grade students in Yogyakarta province of Indonesia in understanding the concept of ionic and covalent bonds. The ionic and covalent bonds were chosen based on the need assessment on chemistry teachers. This study was inclueded qualitative descriptive research which described the level of students' misconceptions. The sample of this study was 56 students of 10th grade students. The sample was selected by using purposive random sampling technique. The data was collected by three-tier diagnostic test. The data was analysed to determine the percentage of misconception level. The results indicated that the 10th grade students in Yogyakarta suffered misconception with high, medium, and low categories of $19.05 \%, 42.86 \%$, and $9.52 \%$, respectively.

Keywords: ionic bond, covalent bond, misconception, three-tier diagnostic test, misconception diagnosis

\section{INTRODUCTION}

Chemistry is one of the sciences that covering concepts, calculations, and combination of both. Some students may experience difficulties in understanding chemistry due to the assumption that chemistry is a difficult subject (Cardellini, 2012; Johnstone, 1991). The assumption that chemistry is a difficult subject could also be caused by its characteristics which is abstract (Horvat, Segedinac, Milenković, \& Hrin, 2016). This is because most chemical concepts are the simplification of the actual situation, for

Citation: Prodjosantoso, A. K., Hertina, A. M., \& Irwanto (2019). The Misconception Diagnosis on Ionic and Covalent Bonds Concepts with Three Tier Diagnostic Test. International Journal of Instruction, 12(1), 1477-1488. https://doi.org/10.29333/iji.2019.12194a 
example, the concept of chemical bonds. Chemical bonds cover the interaction between electrons and their pulling forces. The attractive forces influence the characteristics of compound, such as the boiling point, the melting point, and the solubility in water. The abstract concepts in chemical bonds may cause the students' difficulty in understanding the interactions between electrons.

Simplification of concepts from actual conditions in the form of Lewis structures is intended to help students understanding the concept, although it would confuse some students. This existing confusion is to be the cause of an incompatibility of concepts possessed by the students and the experts. This concept mismatch is commonly called as misconception (de Astudillo \& Niaz, 1996; Hasan, Bagayoko, \& Kelley, 1999; Schmidt, 1994; Tüysüz, 2009).

The misconceptions in chemistry learning are needed to be minimized. Due to interconnection among the chemical concepts, the students experienced misconceptions in one concept would experience the difficulties and the misconceptions (Nicoll, 2001). One of the misconceptions in chemistry learning is a chemical bond. This is in line with Ozmen's study (2004) indicating that a chemical bond is susceptible to a misconception. In addition, the need assessment showed that the most vulnerable year 10 chemistry subject was the chemical bond, that are ionic and covalent bonds.

Identifying the misconceptions experienced by students is a very important step in learning processes (Johnstone, 1991; Taber, 1997). One way to find out the misconception is by using a diagnostic test (Heredia \& Lewis, 2012). A diagnostic test is used to determine the weakness of students' understanding of a concept. A diagnostic test that had been developed in Indonesia is two- and three-tier multiple choice and essay tests. In contrast to previous research, this study used a three-tier diagnostic test, disigned as a branched tree-shaped diagnostic test. A diagnostic test like this was developed by Sekereci (2015) in Turkey but it had not yet been implemented and explained in detail. Therefore, this study would adapt the diagnostic test in the form of branched trees called three-tier diagnostic test to determine the level of misconception and explain in detail the misconceptions experienced by students. The three-tier diagnostic test could reveal the students' understanding fully, including the reasoning ability and the level of confidence. The three-tier diagnostic test may also work as a selfassessment for students by wich the students' weaknesses would be identified and solved to improve students' ability in understanding the concept.

\section{METHOD}

This study was aimed to describe the level students' misconceptions by using the threetier diagnostic test instrument. The first-, the second- and the third-tiers explain the concept of ionic and covalent bonds, the students' reasoning, and the students' level of confidence, respectively.

The population in this study were students of year 10 at Yogyakarta, Indonesia. Whereas, the samples chosen using purposive random sampling technique were students of year 10 SMAN 1 Sewon and SMAN 2 Banguntapan. The selection of the two schools was due to the need assessment of chemistry teachers and the equivalent level of 
cognitive ability between the two schools based on the results of the 2017 National Examination in chemistry subject. The samples were majoring in natural science; with the total number were 56 students.

\section{Data Collection Instrument}

The data were collected using three-tier diagnostic instrument that had been validated by two experts. The validation was done to check the correctness and the approprieteness of the concept in the instrument.

The tool consists of 21 points of diagnostic three-tier instrument. The first-tier describes an explanation of a concept, the second-tier describes the reason of the concept, and the third-tier describes the level of confidence in choosing answers at the first- and secondtiers. In this instrument, students would choose one answer out of two options in each tier, so that three combinations of answers will be obtained for each question, for example: true, true, not sure. The example of the three-tier diagnostic test instrument is presented in Figure 1.

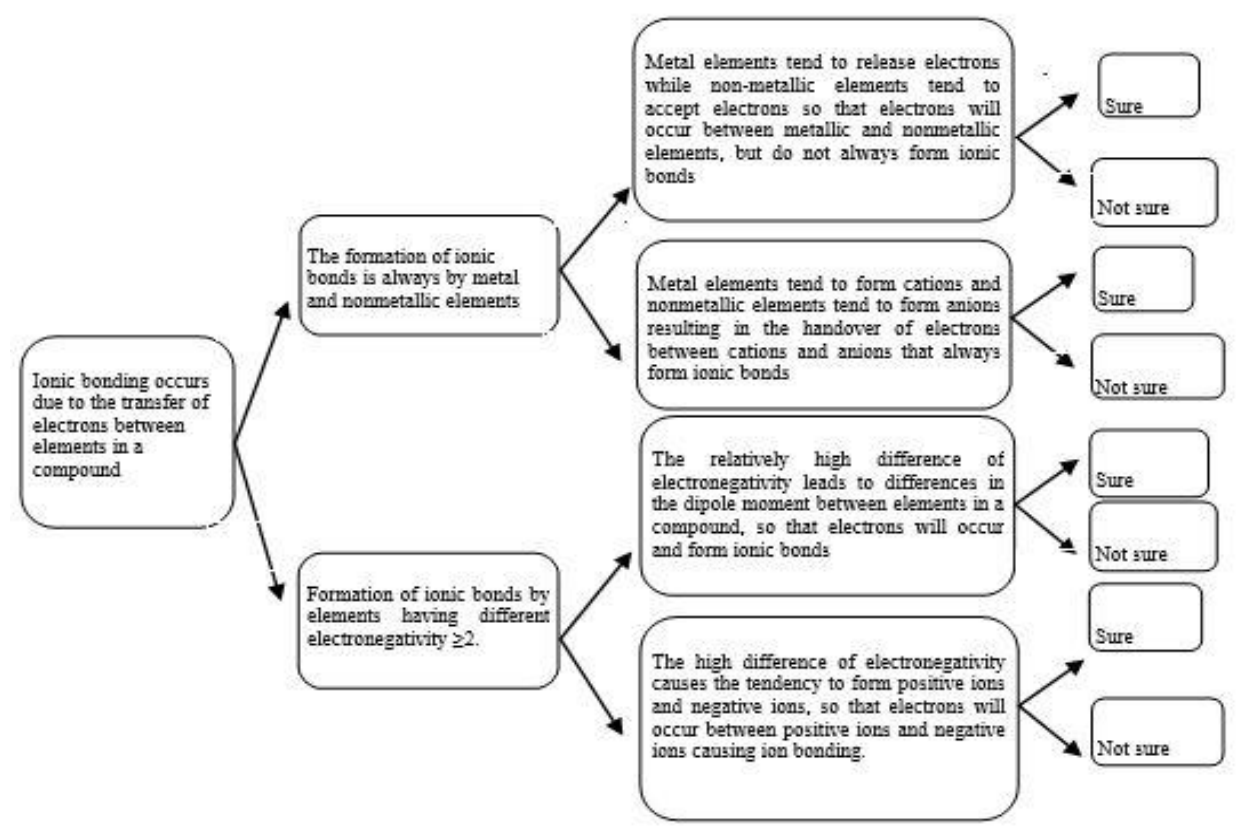

Figure 1

Three-tier diagnostic test

\section{Data Analysis}

Based on the combination of the given answers, the understanding of students' concepts was classified into several categories, such as scientific knowledge, lucky guess, guessing, lack of knowledge, and misconception. The three-tier diagnostic test patterns were presented in Table 1 . 
Table 1

The pattern of three-tier diagnostic test.

\begin{tabular}{|c|c|c|c|}
\hline \multicolumn{4}{|c|}{ Response of Students } \\
\hline $\begin{array}{l}\text { Answer } \\
\text { (First-Tier) }\end{array}$ & $\begin{array}{l}\text { Reason } \\
\text { (Second-Tier) }\end{array}$ & $\begin{array}{l}\text { Confidence } \\
\text { (Third-Tier) }\end{array}$ & Category \\
\hline True & True & Sure & Scientific knowlegde \\
\hline True & True & Unsure & Lucky guess \\
\hline $\begin{array}{l}\text { True } \\
\text { Wrong }\end{array}$ & $\begin{array}{l}\text { Wrong } \\
\text { True }\end{array}$ & $\begin{array}{l}\text { Unsure } \\
\text { Unsure }\end{array}$ & Guessing \\
\hline Wrong & Wrong & Unsure & Lack of knowledge \\
\hline True & Wrong & Sure & \\
\hline Wrong & True & Sure & Misconception \\
\hline Wrong & Wrong & Sure & \\
\hline
\end{tabular}

After obtaining the category for each answer, the percentage of the answers could be calculated. The percentage of answers was calculated for the majority answers given by students for every point of concept. The following was equation used to calculate the percentage of students' answers.

$\mathrm{P}=\frac{s}{N} \times 100 \%$

Notes:

$\mathrm{P}=$ Percentage of the number of students who experience a scientific knowledge, lucky guess, guessing, lack of knowledge, and misconception.

$\mathrm{S}=$ The number of students who experience a scientific knowledge, lucky guess, guess, lack of knowledge, and misconception.

$\mathrm{N}=$ Number of students who done the test.

The results of the percentage of student's answers then were focused on the misconceptions. The level of misconception in understanding ionic and covalent bonds experienced by students was the concern. The level of misconception then was classified into three levels, namely high, medium, and low levels. The classification of misconception levels was presented in Table 2.

Table 2

The level of misconception.

\begin{tabular}{cc}
\hline Percentage & Categories \\
\hline $0-30 \%$ & Low \\
$31-60 \%$ & Medium \\
$61-100 \%$ & High \\
\hline
\end{tabular}

\section{FINDINGS}

\section{The Research Result}

The three-tier diagnostic test was prepared based on the understanding levels of students on the concept of ionic and covalent bonds. The instrument of the study could reveal the students' understanding ability of the ionic and covalent bonds. Therefore, this study 
could be used to minimize the level of misconceptions. The chemistry teacher could determine the best learning process steps. In addition, the next research could refer to this result to develop the better instruments to deepen study misconceptions.

\section{The Research Data}

The data collection was different with previous research. The data described the level of misconceptions and explained the students' misconception in ionic and covalent bonds, meanwhile the previous research done by Sekereci (2015) and Sekereci \& Gecgel (2015) focused on developing of the three-tier instruments and did not fully explained the students' misconceptions. In addition, the research was concluded by calculating the percentages to determine the level of students' misconceptions. The percentage indicated the level of students' mastery on a concept. The percentage of students' answers was presented in Table 3 .

Table 3

The percentage students' misconception.

\begin{tabular}{lll}
\hline The number of the test & Categories & Percentage (\%) \\
\hline 1 & Misconception & 76.79 \\
2 & Scientific Knowledge & 39.29 \\
3 & Misconception & 96.43 \\
4 & Misconception & 71.43 \\
5 & Misconception & 58.93 \\
6 & Misconception & 55.36 \\
7 & Misconception & 51.79 \\
8 & Misconception & 51.79 \\
9 & Misconception & 35.71 \\
10 & Misconception & 57.14 \\
11 & Scientific Knowledge & 48.21 \\
12 & Misconception & 66.07 \\
13 & Scientific Knowledge & 37.5 \\
14 & Misconception & 39.29 \\
15 & Guessing & 37.5 \\
16 & Misconception & 28.57 \\
17 & Misconception & 28.57 \\
18 & Misconception & 48.21 \\
19 & Scientific Knowledge & 30.36 \\
20 & Scientific Knowledge & 64.29 \\
21 & Misconception & 42.86 \\
\hline
\end{tabular}

The misconceptions were explained in detail as follows.

\section{Explanation of ionic bonds formation process}

Metal and non-metal elements in ionic bonds

The misconception occurred because the students failed to understand the ionic bond's composer that was metal and non-metal elements. Whereas there were exceptions to the concept of ion bond formation, in which not all ionic bonds were formed by metal and non-metal elements, such as the $\mathrm{BeCl}_{2}$ compound. The $\mathrm{BeCl}_{2}$ was composed of metal 
and non-metal elements, and the bonds formed were not ionic but covalent bonds. It was because the ionic bond should be viewed based on the difference in electro negativity, i.e. 22.0. (Taber, 1997; Vladušić, Bucatb \& Ožićc, 2013).

Cations and anions in ionic bonds

In general, the misconception was occurred as result of missunderstanding of students thinking about ionic bonds that formed by cations and anions. Whereas there were exceptions to the ionic bond formation concept in which the interaction between cations and anions did not always form of ionic bonds, as in $\mathrm{HCl}$ compound (Hanson, 2015). The interaction between $\mathrm{H}^{+}$ions and $\mathrm{Cl}^{-}$ions did not produce ionic bonds but covalent bonds.

\section{Determining the process of forming ionic in $\mathrm{NaCl}$ compounds}

The ionic bond was viewed based on the interaction between positive ion and negative ions

Misconception occurred because students thought that the ionic bond in $\mathrm{NaCl}$ compound based solely on the interaction between positive ions and negative ions, whereas, ionic bonds in $\mathrm{NaCl}$ compounds were determined based on the electron handover between $\mathrm{Na}$ atoms and $\mathrm{Cl}$ atoms. $\mathrm{Na}$ atoms would release electrons because they tended to have low ionization energies, then the electrons captured by $\mathrm{Cl}$ atoms tended to have electron affinity. Then the electron handover happened and ionic bonds were formed.

Most students took a mistake in understand ionic bonds and covalent bonds, and even tended to understand the upside between ionic and covalent bonds (Ozmen, 2004).

$\mathrm{NaCl}$ ionic bond was viewed based on metal and non-metal elements

Misconception occurred because students thought that the ionic bond in the $\mathrm{NaCl}$ compound was formed from metal and non-metal elements. In fact, the electrons handover happened due to a very large electro negativity difference $\geq 2$ between the $\mathrm{Na}$ and $\mathrm{Cl}$ atoms. In fact, ionic bonds occurred because the electron handover caused by electro negativity difference $\geq 2.0$.

\section{Determining the process of a covalent bond formation}

Covalent bonding was viewed based on the interaction between nonmetal and nonmetal elements

Misconception occurred because the students missed in viewing covalent bonds. They thought it based on the interaction between non-metal and non-metal elements. In fact, covalent bonds should be determined based on the electrons which were not enough in each atom to reach the electron configuration of noble gases. Therefore, each atom would complete its configuration using shared electrons and then formed covalent bonds (Treagust, 1988).

\section{Non-metal could not form cations}

Misconception occurred because students thought that non-metal elements could not form cations. Misconception was possibly happened because of the understanding that non-metal elements were difficult to release electrons so they could not form cations. In 
fact, there was an exception such as $\mathrm{H}$ in the $\mathrm{HCl}$ molecule which could be ionized in water into cations and anions namely $\mathrm{H}^{+}$and $\mathrm{Cl}^{-}$ions (perfect ionization).

Covalent bonds were formed due to the interaction between cations and anions

Misconception occurred because students thought covalent bonds were formed due to the interaction between cations and anions. In fact, the interaction between cations and anions tended to occur in ionic bonds but not in covalent bonds. Covalent bonds occurred because of sharing of electron pairs in order to achieve stability.

\section{Determining the process of bond formation in $\mathrm{NH}_{4} \mathrm{Cl}$ compounds}

Bonds in $\mathrm{NH}_{4} \mathrm{Cl}$ compounds were based on Lewis structures

Misconception occurred because of the incompleteness concept in explaining the bond of $\mathrm{NH}_{4} \mathrm{Cl}$ compound. Students thought that the bond in the $\mathrm{NH}_{4} \mathrm{Cl}$ compound was based on the Lewis structure so it made covalent bond. In fact, the formation of bonds in the $\mathrm{NH}_{4} \mathrm{Cl}$ compound was not only based on the Lewis structure but the interaction between $\mathrm{NH}_{4}{ }^{+}$ions and $\mathrm{Cl}^{-}$ions which was made an ionic bond.

The ionic bond in the $\mathrm{NH}_{4} \mathrm{Cl}$ compound was based on the interaction of metal and nonmetal elements

Misconception occurred because students thought the ionic bonds in the $\mathrm{NH}_{4} \mathrm{Cl}$ compound were based on the interaction between metal and non-metal elements. In fact, ionic bonds in $\mathrm{NH}_{4} \mathrm{Cl}$ should be viewed based on the interaction between polyatomic cations namely $\mathrm{NH}_{4}^{+}$with anions namely $\mathrm{Cl}^{-}$. Misconception in ionic bonds was possible because the understanding of ionic bonds was only into the interaction between metal and non-metal elements. Therefore, this misconception was affected by prior knowledge on ionic bonds (Ballester Pérez et al., 2017).

\section{Determining the interaction of $\mathrm{HCl}$ compounds}

\section{Ionic bonds in $\mathrm{HCl}$ molecules}

Misconception occurred because students thought that the bond in $\mathrm{HCl}$ compound was an ionic bond. In fact that the bond to the $\mathrm{HCl}$ compound was a polar covalent bond (Yayon, Mamlok-naaman, \& Fortus, 2012). The misconception was possible because the understanding of students did not look at the distribution of electrons between $\mathrm{H}$ atoms and $\mathrm{Cl}$ atoms.

Covalent bond was based on nonmetal elements that were difficult to release electrons

Misconception occurred because students thought that a covalent bond was based on the interaction of metal elements with non-metals, whereas non-metal elements that were difficult to release electrons. In fact, the interaction of metal elements with non-metal elements did not show the formation of covalent bonds. In addition, there was an exception that non-metal elements were difficult to release electrons, such as $\mathrm{H}$ atoms tended release electrons.

Determining the polarity of a compound

The molecular geometry of symmetry and asymmetry always indicate the polarity of a compound 
Misconception occurred because of the incompleteness concept in explaining the polarity of a compound. Students thought that the molecular geometry of symmetry and symmetry always showed the polarity of a compound, such as the molecular geometry of symmetry showing non-polar covalent bonds and the formed of asymmetric molecules showing polar covalent bonds. In fact, the polarity of a compound could not always be determined based on the molecular geometry of symmetry or asymmetry.

Changing in molecular geometry caused the polarity of a compound was different

Misconception occurred because of students' misunderstanding of the polarity of a compound. Students thought that changing in molecular geometry would change the polarity of a compound. In fact, polarity of a compound was not determined by change in molecular geometry. Polar compounds could not change into non-polar compounds due to change in molecular geometry, or non-polar compounds could not change into polar compounds due to change in molecular geometry.

\section{Determining the non-polar molecules}

Vector direction in determining dipole moments led to atoms which made anions

Misconception occurred because students thought that in determining the dipole moment, the vector direction led to the atoms which made anions. In fact, there were two atoms that could form anions in a molecule, such as $\mathrm{SO}_{3}$ molecules. Therefore, the direction of the vector should lead to the most electronegative atom.

Polar covalent bonds showed a polar molecule

Misconception occurred because of incompleteness of concepts that were owned by students. Students determined polar molecules based there was a polar covalent bond in a molecule. In fact, there was a polar covalent bond did not always show polar molecules, as in $\mathrm{CO}_{2}$ molecules. Therefore, it was necessary for finding dipole moments which was produce in a molecule.

\section{Determining the covalent bonds}

The $\mathrm{SO}_{3}$ molecules were formed from double covalent bonds and coordinate covalent bonds

Misconception occurred because of incompleteness concept in explaining the bonds that occurred in $\mathrm{SO}_{3}$ molecules. Students only mentioned that the $\mathrm{SO}_{3}$ molecule consisted of double covalent bonds and coordination covalent bonds, but it was not explain how many bonds occurred. In fact, there were three bonds in a $\mathrm{SO}_{3}$ molecule, namely two coordination covalent bond and double covalent bond.

The $\mathrm{SO}_{3}$ molecule was consisted of three duplicate covalent bonds, as in the $\mathrm{SO}_{2}$ molecule

Misconception occurred because of the associations made by students. They thought that the bonds in a $\mathrm{SO}_{3}$ molecule was the same as in the $\mathrm{SO}_{2}$ molecule, which was a double covalent bond. In fact, in a $\mathrm{SO}_{3}$ molecule there were also two coordination covalent bonds. 


\section{Bonds in $\mathrm{NH}_{3}$ and $\mathrm{CO}_{2}$ molecules}

There was covalent coordination in a $\mathrm{NH}_{3}$ molecule

Misconceptions occurred because students' misunderstanding when determining the Lewis structure of a NH3 molecule. Students thought that the $\mathrm{N}$ atom in the $\mathrm{NH}_{3}$ molecule had non-bonding electron which indicated a covalent coordination bond. In fact, there was non-bonding electron did not always cause form a covalent coordination bond. Whereas $\mathrm{N}$ atoms had bounded one electron from each $\mathrm{H}$ atom and formed was a single covalent bond.

Bonds in $\mathrm{NH}_{3}$ and $\mathrm{CO}_{2}$ molecules were looked based on the electron quantities surrounding the central atom

Misconception was caused by students thought that covalent bonds were seen based on the number of electrons surrounding the central atom. In fact, not all electrons that surrounded the central atom would bind to other atoms. Therefore, the bond was formed due to bonding electron (Chandrasegaran, Treagust, \& Mocerino, 2007)

The process of forming covalent bonds in $\mathrm{NH}_{3}$ and $\mathrm{CO}_{2}$ molecules

Misconception was ensued because students thought the covalent bonds in $\mathrm{NH}_{3}$ molecule because of $\mathrm{N}$ atom contributed three electrons to the $\mathrm{H}$ atom. In fact, only one electron was donated by $\mathrm{N}$ atom to each $\mathrm{H}$ atom, so it was formed by three single

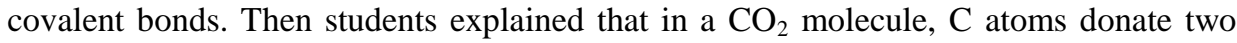
electrons to an $\mathrm{O}$ atom. Even though, there were two atoms in a $\mathrm{CO}_{2}$ molecule. Therefore, the bonds formation was looked by $\mathrm{C}$ atoms donated two electrons to each $\mathrm{O}$ atom.

\section{Determining the polarity of a molecule based on differences in electronegativity}

The difference of electro negativity always showes the polarity of a molecule

Misconception happened because of incompleteness of the concepts in explaining the polarity. Students thought that the difference in electro negativity of a compound would show the polarity of a molecule. In fact, there was not always electro negativity difference showed the polarity of a molecule (Nimmermark \& Lars, 2016).

The electro negativity difference was formed from metal and non-metal elements

Misconception occurred because students thought that electro negativity differences were formed from metal and non-metal elements. In fact, there were exceptions in these concepts, such as in $\mathrm{HCl}$ molecules. The electro negativity difference formed was formed by non-metal and non-metal elements. Therefore, the difference of electro negativity was not always formed by metal and non-metal elements, such as in $\mathrm{HCl}$ molecules.

\section{Determining the covalent bond on $\mathrm{NH}_{3} \mathrm{BF}_{3}$ compounds}

Coordination covalent bond was formed between non-metal elements and non-metal elements

Misconception occurred because students thought that coordination covalent bonds were formed by non-metal with non-metal elements. In fact, the interaction between nonmetals and non-metals elements did not always form a covalent coordination bond. It 
should be viewed through the use of a pair of electrons shared from one atom in order to achieve stability.

\section{Determining the characteristic of ionic compounds on $\mathrm{Na}_{2} \mathrm{O}$}

The external forces caused ions not to be easily separated

Misconception was caused by the students' misunderstanding in ionic compounds' characteristic (Taber, 1997; Nimmermark \& Lars, 2016). They thought that the external forces caused the ions were not separated easily. In fact, the external forces caused ions separated easily because of the changing the ions position. This changing was caused of the previous ions attracted with other ions became to repulsive force due to the influence of external forces (Barker \& Millar, 2000).

Forming of $\mathrm{Na}_{2} \mathrm{O}$ solids would be ionized into cations and anions

Misconception was caused by the students' misunderstanding in ionization concept. They thought that the form of solids an ionic compound could be ionized. In fact, in the form of solids a compound could not be ionized into cations and anions. Ionization was occured when a solid was dissolved in water and ionizes into its ions.

\section{Determining the boiling point in covalent bonds}

The weak attraction in covalent bonds because of forming non-metal and non-metal elements

Misconception happened because students thought that the covalent bonds had weak attraction due to be formed from non-metal and non-metal elements. In fact, the boiling point tended to be lower than the ionic bonds because there was no electrostatic force in the covalent bonds as in the ionic bonds, so the energy needed to separate the bond was not so large and affects the boiling point which tends to be lower.

The low boiling point was caused by a very weak pulling force on covalent bonds

Misconception occurred because students thought that the attractive force on covalent bonds was very weak. In fact, the attraction in covalent bonds was strong but the force between molecules in covalent bonds was weak. This force between weak molecules caused the boiling point of the covalent bond to be lower than the ion bond.

\section{Determining the bonds in $\mathrm{KOH}$ and $\mathrm{NaNO}_{3}$ compounds}

$\mathrm{KOH}$ and $\mathrm{NaNO}_{3}$ compounds only had ionic bonds

Misconception happened because students did not fully explain the bonds that were occurred in $\mathrm{KOH}$ and $\mathrm{NaNO}_{3}$. Students thought that $\mathrm{KOH}$ and $\mathrm{NaNO}_{3}$ compounds only had ionic bonds. In fact, these two compounds also had covalent bonds. The covalent bonds were occurred in $\mathrm{O}$ and $\mathrm{H}$ atoms of $\mathrm{KOH}$ and in $\mathrm{O}$ and $\mathrm{N}$ atoms of $\mathrm{NaNO}_{3}$ compounds.

The ionic bonds in the $\mathrm{NaNO}_{3}$ and $\mathrm{KOH}$ compounds were formed from metal and nonmetal elements

Misconception occurred because the students' understanding was wrong about the formation of ionic bonds in $\mathrm{NaNO}_{3}$ and $\mathrm{KOH}$ compounds. Students thought the ionic bonds in $\mathrm{NaNO}_{3}$ and $\mathrm{KOH}$ compounds due to the interaction between metal and nonmetal elements (Hanson, 2015). In fact, the ionic bonds occurred because of the interactions of $\mathrm{K}^{+}$ions with $\mathrm{OH}^{-}$ions and $\mathrm{Na}^{+}$ions with $\mathrm{NO}_{3}{ }^{-}$ions. 
The bond of $\mathrm{O}$ and $\mathrm{N}$ in the $\mathrm{NaNO}_{3}$ compound was a covalent coordination relationship Misconception was ensued because students' misunderstanding in concept of covalent bonds in $\mathrm{NaNO}_{3}$ compound. Students thought that the bond between $\mathrm{O}$ and $\mathrm{N}$ atom in $\mathrm{NaNO}_{3}$ compound was a coordination covalent bond. In fact, the bond between them was a covalent bond, not a covalent coordination bond.

\section{CONCLUSION}

Based on the results of the research that had been done it could be concluded that $10^{\text {th }}$ grade students of Senior high school in Bantul region experienced high category misconceptions of $19.05 \%$, medium category $42.86 \%$ and low category of $9.52 \%$.

\section{REFERENCES}

Ballester Pérez, J. R., Ballester Pérez, M. E., Calatayud, M. L., García-Lopera, R., V., S. M. J., \& Trilles Gil, E. (2017). Student's Misconceptions on Chemical Bonding: a Comparative Study Between High School and First Year University Students. Asian Journal of Education and E-Learning, 5(1), 1-15.

Barker, R., \& Millar, V. (2000). Students' Reasoning about Basic Chemical Thermodynamics and Chemical Bonding: What Changes Occur During a Context-Based Post-16 Chemistry Course? International Journal Science Education, 22(11), 11711200 .

Cardellini, L. (2012). Chemistry: Why the subject is difficult? Educación Química, 23, 305-310. https://doi.org/10.1016/S0187-893X(17)30158-1

Chandrasegaran, A. L., Treagust, D. F., \& Mocerino, M. (2007). The development of a two-tier multiple-choice diagnostic instrument for evaluating secondary school students' ability to describe and explain chemical reactions using multiple levels of representation (Vol. 8).

de Astudillo, L. R., \& Niaz, M. (1996). Reasoning Strategies Used by Students to Solve Stoichiometry Problems and Its Relationship to Alternative Conceptions, Prior Knowledge, and Cognitive Variables. Journal of Science Education and Technology, 5(2), 131-140.

Gecgel, G \& Sekereci, A. R. (2015). Developing a Concept Test for Chemistry Topics by Using the Diagnostic Branched Tree (DBT) Technique. Oxidation Communications, 38, 530-539.

Hanson, R. (2015). Identifying Students' Alternative Concepts in Basic Chemical Bonding - A Case Study of Teacher Trainees in the University of Education, Winneba. International Journal Innovative Research \& Development, 4(1), 115-122.

Hasan, S., Bagayoko, D., \& Kelley, E. L. (1999). Misconceptions and the certainty of response (CRI). Physics Education, 34(5), 294-299.

Heredia, K., \& Lewis, J. E. (2012). Research and practice the application and evaluation of a two-concept diagnostic instrument with students entering college general chemistry. https://doi.org/10.1039/c0rp90017

Horvat, S., Segedinac, M. D., Milenković, D. D., \& Hrin, T. N. (2016). Development of Procedure for the Assessment of Cognitive Complexity of Stoichiometric Task. 
Macedonian Journal of Chemistry and Chemical Engineering, 35(2), 275-284. https://doi.org/10.20450/mjcce.2016.893

Johnstone, A. H. (1991). Seldom What They Seem. Journal of Computer Assisted Learning, 7, 75-83.

Nicoll, G. (2001). A Report of Undergraduates Bonding Misconceptions. International Journal of Science Education, 23(7), 707-730. https://doi.org/10.1080/ 09500690010025012

Nimmermark, A., \& Lars, O. (2016). Teaching of Chemical Bonding: A Study of Swedish and South African Students' Conceptions of Bonding. Journal Chemistry Education Research and Practice, 1-21. https://doi.org/10.1039/C6RP00106H

Ozmen, H. (2004). Some Student Misconceptions in Chemistry. Journal of Science Education Technology, 13(2), 1998-1999.

Schmidt, H. J. (1994). Stoichiometric Problem Solving in High School Chemistry Stoichiometric Problem Solving in High School Chemistry. International Journal of Science Education, 16(2), 191-200.

Sekereci, A. R. (2015). Development of Diagnostic Branched Tree Test for High School Chemistry. Oxidation Communications, 38, 1060-1067.

Suwarna. (2014). Analisis miskonsepsi siswa kelas x pada materi pelajaran fisika melalui CRI (certainty of respone index) termodifikasi. Jurnal Lemit.

Taber, K. S. (1997). Student Understanding of Ionic Bonding: Molecular Versus Electrostatic Thinking. School Science Review, 78(285), 85-95.

Taber, K. S. (1998). An Alternative Conceptual Framework from Chemistry Education. International Journal of Science Education, 20(5), 597-608. https://doi.org/10.1080/ 0950069980200507

Treagust, D. F. (1988). Development and Use of Diagnostic Tests to Evaluate Students' Misconceptions in Science. International Journal of Science Education, 10(2), 159169. https://doi.org/10.1080/0950069880100204

Tüysüz, C. (2009). Development of Two-Tier Diagnostic Instrument and Assess Students' Understanding in Chemistry. Academic Journals, 4(6), 626-631.

Vladušić, R., Bucatb R. B., \& Ožićc, M. (2013). Understanding Ionic Bonding- A Scan Across the Croation Education System. Chemistry Education Research and Practice, 114. https://doi.org/10.1039/C6RP00040A

Wu, H., Krajcik, J. S., \& Soloway, E. (2001). Promoting Understanding of Chemical Representations: Students Use of a Visualization Tool in the Classroom. Journal of Research in Science Teaching, 38(7), 821-842.

Yayon, M., Mamlok-naaman, R., \& Fortus, D. (2012). Research and Practice Characterizing and Representing Student's Conceptual Knowledge of Chemical Bonding. Journal of Chemistry Education Research and Practice, 13, 248-267. https://doi.org/ 10.1039/c0rp90019b 